\title{
Psychosocial Aspects of Immediate versus Delayed Breast Reconstruction
}

\author{
Anne-Sophie Heimes Kathrin Stewen Annette Hasenburg \\ Department of Obstetrics and Gynecology, University Medical Center, Mainz, Germany
}

\section{Keywords}

Breast cancer surgery .

Immediate vs. delayed reconstruction - Mastectomy . Quality of life

\section{Summary}

Background: Only little is known about the psychosocial aspects of breast cancer patients after mastectomy with immediate versus delayed breast reconstruction. Methods: We systematically screened PubMed using the following key words: mastectomy, immediate vs. delayed reconstruction, psychosocial aspects and quality of life. To highlight different psychological outcomes, studies were categorized into those describing: anxiety, depression, body image and satisfaction with the surgical outcome. We also compared patients after mastectomy alone with those undergoing immediate or delayed reconstruction. Results: Methodologies and psychological outcomes varied among the identified studies, making it difficult to compare results. There are contradictory outcomes concerning the psychosocial aspects of breast cancer patients after mastectomy alone compared with those who underwent an immediate or delayed reconstruction following mastectomy. Some studies show that immediate reconstruction after mastectomy had a positive impact on patients' psychological well-being. In contrast, other studies indicated that in the long-term view the compared patient groups were very similar concerning psychosocial aspects. Conclusion: Analyzing different aspects of psychosocial well-being after breast cancer surgery, there might be an advantage in choosing immediate reconstruction, if oncological safety allows it.

\section{Introduction}

Breast cancer is the most common cancer in women. In 2013, 74,600 patients were diagnosed with breast cancer in Germany [1]. Concerning effectiveness and survival, breast-conserving surgery followed by radiation is equivalent to mastectomy [2]. Due to medical contraindications to breast-conserving surgery, about $30 \%$ of women face mastectomy. Little is known about psychosocial aspects of patients who undergo a mastectomy. This article reviews current findings on different surgical techniques as well as the different timing of surgical intervention. After mastectomy, there are several surgical techniques for reconstruction, such as reconstruction using implants or reconstruction with the woman's own tissue (e.g. transverse rectus abdominis myocutaneous flap (TRAM Flap), latissimus dorsi flap with or without the concomitant use of implants, and deep inferior epigastric perforator flap). Furthermore, there are different options for timing a reconstructive surgery: immediately with the mastectomy or delayed in a separate surgery. Based on the findings of a current population-based observation study of Platt et al. [3], 23.3\% of breast cancer patients decide to undergo reconstructive surgery after mastectomy, $11.7 \%$ of whom choose immediate breast reconstruction and $11.6 \%$ prefer delayed reconstruction within 3 years after mastectomy. Treatment options depend on patient's health circumstances, adjuvant systemic therapy and whether additional radiotherapy is required. If it is unlikely that the patient requires additional radiotherapy, immediate reconstruction following mastectomy is the first choice of treatment.

\section{Methods}

We systematically reviewed literature by screening PubMed using following key words: mastectomy, immediate vs. delayed reconstruction, psychosocial aspects and quality of life. Methodologies and psychological outcomes varied among identified studies, making it difficult to compare results. In order to highlight different psychological outcomes and ensure transparency, we catego-

\section{KARGER}

() 2017 S. Karger GmbH, Freiburg

Fax +497614520714
Dr. med. Anne-Sophie Heime 
Table 1. Overview of the studies and questionnaires used to assess different psychosocial aspects in patients after breast cancer surgery

\begin{tabular}{|c|c|c|c|c|c|c|c|c|c|}
\hline Study & Study type & $\begin{array}{l}\text { Patients, } \\
\mathrm{n}\end{array}$ & BCT & $\begin{array}{l}\text { Mast. } \\
\text { alone }\end{array}$ & $\begin{array}{l}\text { Mast. with } \\
\text { reconstruction }\end{array}$ & Anxiety & Depression & Body image & $\begin{array}{l}\text { Quality of } \\
\text { life }\end{array}$ \\
\hline $\begin{array}{l}\text { Nissen et al. } \\
\quad[5]\end{array}$ & Prospective & 198 & $\mathrm{x}$ & $\mathrm{x}$ & $\mathrm{x}$ & POMS & POMS & FACT-B & MUIS \\
\hline $\begin{array}{l}\text { Shekhwat } \\
\text { et al. [17] }\end{array}$ & Prospective & 150 & & $\mathrm{x}$ & $\mathrm{x}$ & BREAST-Q & BREAST-Q & BREAST-Q & BREAST-Q \\
\hline $\begin{array}{l}\text { Harcourt } \\
\quad \text { et al. [15] }\end{array}$ & Prospective & 103 & & $\mathrm{x}$ & $\mathrm{x}$ & $\begin{array}{l}\text { Hospital Anxiety and } \\
\text { Depression Scale }\end{array}$ & $\begin{array}{l}\text { Hospital Anxiety and } \\
\text { Depression Scale }\end{array}$ & $\begin{array}{l}\text { Body Image } \\
\text { Scale }\end{array}$ & $\begin{array}{l}\text { EORTC } \\
\text { QLQ-30 }\end{array}$ \\
\hline $\begin{array}{l}\text { Metcalfe et } \\
\quad \text { al. [7] }\end{array}$ & Prospective & 67 & & $\mathrm{x}$ & $\mathrm{x}$ & BSI, IES & BSI & $\mathrm{BIBC}$ & QLI \\
\hline $\begin{array}{l}\text { Metcalfe } \\
\quad \text { et al [8] }\end{array}$ & Prospective & 190 & & $\mathrm{x}$ & $\mathrm{x}$ & BSI, IES & BSI & BIBC & QLI \\
\hline $\begin{array}{l}\text { Roth et al. } \\
\quad[10]\end{array}$ & Prospective & 295 & & $\mathrm{x}$ & $\mathrm{x}$ & $\begin{array}{l}\text { BSI, Modified } \\
\text { Somatic Perception } \\
\text { Questionnaire }\end{array}$ & BSI & & \\
\hline $\begin{array}{l}\text { Parker } \\
\quad \text { et al. [6] }\end{array}$ & Prospective & 258 & $\mathrm{x}$ & $\mathrm{x}$ & $\mathrm{x}$ & STAI & CES-D & MBSRQ & $\begin{array}{l}\text { MBSRQ, } \\
\text { SF36 }\end{array}$ \\
\hline $\begin{array}{l}\text { Wellisch } \\
\quad \text { et al. [18] }\end{array}$ & Retrospective & 63 & & & $\mathrm{x}$ & $\begin{array}{l}\text { BSI, psychosocial } \\
\text { reactions to different } \\
\text { types of breast } \\
\text { cancer surgery }\end{array}$ & $\begin{array}{l}\text { BSI, psychosocial } \\
\text { reactions to different } \\
\text { types of breast } \\
\text { cancer surgery }\end{array}$ & & \\
\hline $\begin{array}{l}\text { Al Ghazal et } \\
\text { al. [9] }\end{array}$ & Retrospective & 577 & & & $\mathrm{x}$ & $\begin{array}{l}\text { Hospital Anxiety and } \\
\text { Depression Scale }\end{array}$ & $\begin{array}{l}\text { Hospital Anxiety and } \\
\text { Depression Scale }\end{array}$ & $\begin{array}{l}\text { Body Image } \\
\text { Scale }\end{array}$ & \\
\hline
\end{tabular}

${ }^{\mathrm{a}}$ Immediate/delayed reconstruction.

$\mathrm{BCT}=$ breast-conserving therapy, Mast. = mastectomy, BIBC $=$ body image after breast cancer, BSI $=$ Brief Symptom Inventory, CES-D = Center for Epidemiological Studies-Depression, EORTC QLQ-30 = European Organization for Research and Treatment of Cancer Quality of life questionnaire-breast cancer module, FACT B = Functional Assessment of Cancer Therapy for patients with breast cancer, IES = Impact of event scale, MBSRQ = Multidimensional Body-SelfRelations Questionnaire-Appearance, MUIS = Mishel Uncertainty in Illness Scale, POMS = Profile of Mood States, QLI = quality of life index, SF36 = Medical Outcomes Study 36-item Short Form Survey, STAI = State-Trait Anxiety Inventory.

rized the studies into the following groups: anxiety, depression, body image, and satisfaction with the surgical outcome. Additionally, we compared patients after mastectomy alone with those who underwent immediate or delayed reconstruction (table 1).

\section{Results}

\section{Anxiety}

Women who receive a diagnosis of breast cancer have high levels of anxiety. Goldberg et al. [4] indicated that $50 \%$ of women who underwent any type of breast cancer surgery complained of severe levels of anxiety, with a third of them still reporting psychological issues 1 year after surgery. In a prospective study, Nissen et al. [5] assessed the degree of anxiety using the POMS (Profile of Mood States) questionnaire in a cohort of 198 patients. Levels of anxiety were compared across 3 groups of patients: those who underwent breast-conserving surgery, mastectomy alone, or mastectomy with reconstruction. The results showed that patients with reconstructive surgery had significantly higher levels of mood disturbance than patients with mastectomy without reconstruction. Furthermore, patients who underwent breast-conserving surgery complained of higher levels of tension and anxiety than patients with mastectomy alone.
In a prospective study that included 258 patients, Parker et al. [6] evaluated the short- and long-term effects of mastectomy with reconstruction, mastectomy without reconstruction and breastconserving surgery on psychosocial aspects. The authors assessed depressive symptoms, anxiety, body image, body satisfaction, sexual functioning and quality of life using validated questionnaires. Instruments used included the STAI (State-Trait Anxiety Inventory), CES-D (Center for Epidemiological Studies - Depression), MBSRQ (Multidimensional Body-Self-Relations QuestionnaireAppearance) and SF36 (Medical Outcomes Study 36-item Short Form Survey). The latter was used as a measurement for quality of life. Results revealed that levels of anxiety already decreased 1 month after surgery but did not differ by surgery group.

In contrast, a prospective study of Metcalfe et al. [7] demonstrated that women with delayed breast reconstruction had significantly higher levels of anxiety in comparison to patients with mastectomy alone. In another prospective study, Metcalfe et al. [8] analyzed aspects of psychosocial functioning 1 year after mastectomy alone, delayed breast reconstruction, or immediate breast reconstruction. At 1 year after the beginning of the study, there were no differences in psychosocial functioning (anxiety, cancerrelated distress, body image, quality of life) between the 3 analyzed groups. 
In a large retrospective analysis, $\mathrm{Al}$ Ghazal et al. [9] examined the psychological advantages of immediate reconstruction versus delayed reconstruction in 577 patients. Validated questionnaires assessed anxiety, depression, body image, self-esteem, sexuality and satisfaction. Results showed that anxiety and depression were lower but body image, self-esteem, and satisfaction were significantly higher in the immediate reconstruction group compared to the delayed reconstruction group.

\section{Depression}

Analyzing the different psychosocial aspects in patients after breast surgery, depression seems to be an important factor limiting the patient's quality of life [10]. In a prospective study, Metcalfe et al [7]. studied psychosocial aspects in 67 mastectomy patients with and without delayed reconstruction over 3 different points in time (pre-mastectomy, 1 year post-mastectomy, long-term post-mastectomy) using validated questionnaires. These were the QLI (Quality of Life Index), BIBC (Body Image after Breast Cancer), IES (Impact of Event Scale) and BSI (Brief Symptom Inventory). The BSI measures current feelings of psychological distress, such as depression, anxiety, somatization, obsessive-compulsive actions, interpersonal sensitivity, hostility, psychoticism, phobic anxiety and paranoid ideation. Results showed that, at long-term follow-up, women with delayed breast reconstruction felt significantly higher levels of overall distress and, in particular, had more depressive symptoms than patients with immediate reconstruction [7].

In the study by Al Ghazal et al. [9] mentioned above, the authors investigated the psychological impact of immediate compared to delayed breast reconstruction. They found depression was notably lower in patients with immediate reconstruction compared to those with delayed reconstruction. They also showed that patients with immediate reconstruction felt significantly less distress and overall experienced better psychosocial well-being compared to the patients with delayed reconstruction.

\section{Body Image and Satisfaction}

Previous studies revealed that patients with mastectomy without reconstruction have poorer body image and, therefore, more limited sexual function compared to breast-conserving surgery patients [11-13].

In a prospective study including 158 patients, Metcalfe et al. [8] assessed patients at 2 different time points (pre-surgery and 1 year after surgery). Using validated questionnaires, the authors measured body image, quality of life, sexual activity, cancer-related distress, body image, depression, and anxiety among those who underwent mastectomy alone, or mastectomy with immediate or delayed reconstruction. Concerning body image, the results showed that women with delayed reconstruction had higher levels of body stigma and body concerns compared to women with immediate reconstruction. In this context, body stigma refers to the feeling 'the need to keep the body hidden and to avoid physical intimacy'.

The aim of another prospective study by Parker et al. [6] was to analyze psychosocial items, e.g. body image, body satisfaction, sexual functioning, quality of life and depressive symptoms, using validated questionnaires (CES-D, STAI, MBSRQ, and SF36) at 5 different points in time: before surgery, and again 1, 6, 12 and 24 months after surgery. The authors compared 3 groups of surgery procedures: mastectomy with reconstruction, mastectomy without reconstruction and breast-conservation therapy. Results revealed that all 3 groups reported a decrease of positive body image 1 month after surgery, which recovered in the long term. Overall, there were no significant differences between the 3 surgical procedures.

In a prospective study of Dean et al. [14], women with immediate reconstruction had a significant better body image and felt greater freedom of dress. This effect was predominantly seen in women with unsatisfactory marriages. This is in line with the results of the retrospective study of Al Ghazal et al. [9] in which they evaluated psychosocial aspects of immediate versus delayed reconstruction in 577 breast cancer patients. Using validated questionnaires, the patients reported levels of depression, body image, selfesteem, sexuality and satisfaction. The study showed that body image, self-esteem, sexual feeling, attractiveness and satisfaction were notably higher in the patients who underwent immediate reconstruction compared to those who had a delayed reconstruction.

In contrast, a prospective study by Harcourt et al. [15] that included 103 patients and evaluated the psychosocial effects following mastectomy with or without breast reconstruction showed that surgery procedure (with or without reconstruction) had no influence on body image.

\section{Discussion}

Due to the heterogeneity within utilized measurements among different studies, the comparison of different studies remained a challenge. For example, some authors created their own questionnaires, while others used standardized but different questionnaires to assess common psychosocial outcomes (anxiety, depression, etc.).

In 2010, Chen et al. [16] analyzed the existing patient-reported outcome measures in oncological breast surgery. The results of this review revealed that existing studies failed to cover the full range of psychosocial issues that breast cancer patients face after different types of surgery.

Overall, we believe the questionnaire Breast $\mathrm{Q}$ provides the most comprehensive assessment of different psychosocial aspects after oncological breast surgery [17]. However, small sample sizes, missing control groups, different times of administering questionnaires and the small number of prospective studies contributed to challenges in comparing results for patients who underwent mastectomy with immediate versus delayed reconstruction. In particular, in earlier studies, a baseline of psychological testing before surgery was missing.

In conclusion, our overall impression is that there might be an advantage in choosing immediate reconstruction, if oncological justifiable. Psychological assistance should be offered to all patients with any type of breast cancer surgery. 


\section{Disclosure Statement}

The authors have no conflicts of interest.

\section{References}

1 Bericht zum Krebsgeschehen in Deutschland 2016, chapter 2. Robert Koch Institute, Berlin, p. 26

2 Fisher B, Redmond C, Poisson R, et al.: Eight-year results of a randomized clinical trial comparing total mastectomy and lumpectomy with or without irradiation in the treatment of breast cancer. N Engl J Med 1989;320:822-828.

3 Platt J, Zhong T, Moineddin R, et al.: Geographic variation immediate and delayed breast reconstruction utilization in Ontario, Canada and plastic surgeon availability: A population- based observational study. World J Surg 2015;39:1909-1921.

4 Goldberg JA, Scott RN, Davidson PM, et al.: Psychological morbidity in the first year after breast cancer surgery. Eur J Surg Oncol. 1992;18:327-331.

5 Nissen MJ, Swenson KK, Ritz LJ, et al.: Quality of life after breast carcinoma surgery: A comparison of three surgical procedures. Cancer 2001;91:1238-1246.

6 Parker PA, Youssef A, Walker S, et al.: Short-term and long-term psychosocial adjustment and quality of life in women undergoing different surgical procedures for breast cancer. Ann Surg Oncol 2007;14:3078-3089.
7 Metcalfe KA, Zhong T, Narod SA, et al.: A prospective study of mastectomy patients with and without delayed breast reconstruction: long-term psychosocial functioning in the breast cancer survivorship period. J Surg Oncol 2015;111:258-264.

8 Metcalfe KA, Semple J, Quan ML, et al.: Changes in psychosocial functioning 1 year after mastectomy alone, delayed breast reconstruction, or immediate breast reconstruction. Ann Surg Oncol 2012;19:233-241.

9 Al Ghazal SK, Sully L, Fallowfield L, et al.: The psychological impact of immediate rather than delayed breast. Eur J Surg Oncol 2000;26:17-19.

10 Roth RS, Lowery JC, Davis J, Wilkins EG: Psychological factors predict patient satisfaction with postmastectomy breast reconstruction. Plast Reconstr Surg 2007; 119:2008-2015.

11 Kiebert GM, de Haes JC, van de Velde CJ, et al.: The impact of breast-conserving treatment and mastectomy on the quality of life of early-stage breast cancer patients: A review. J Clin Oncol 1991;9:1059-1070.

12 Kissane DW, Clarke DM, Ikin J, et al.: Psychological morbidity and quality of life in Australian women with early-stage breast cancer: a cross-sectional survey. Med J Aust 1998;169:192-196.
13 Janni W, Rjosk D, Dimpfl TH, et al.: Quality of life influenced by primary surgical treatment for stage I-II breast cancer-long-term follow-up of a matched-pair analysis. Ann Surg Oncol 2001;8:542-548.

14 Dean C, Chetty U, Forrest AP: Effects of immediate breast reconstruction on psychosocial morbidity after mastectomy. Lancet 1983;1:459-462.

15 Harcourt D, Rumsey N, Ambler NR, et al.: The psychological effect of mastectomy with or without breast reconstruction: A prospective multicenter study. Plast Reconstr Surg 2003;111:1060-1067.

16 Chen C, Cano S, Klassen AF, et al.: Measuring quality of life in oncologic breast surgery: A systematic review of patient-reported outcome measures. Breast J 2010 16:587-597.

17 Shekhawat L, Busheri L, Dixit S, et al.: Patient-reported outcomes following breast reconstruction surgery and therapeutic mammoplasty: Prospective evaluation 1 year post-surgery with BREAST-Q questionnaire. Indian J Surg Oncol 2015;6:356-362.

18 Wellisch DK, Schain WS, Noone RB et al.: Psychosocial correlates of immediate versus delayed reconstruction of the breast. Plast Reconstr Surg 1985:76:713718. 